\title{
Medicalização, bioeconomia e processos de subjetivação: algumas considerações sobre a governamentalidade neoliberal no mercado de saúde
}

\author{
Medicalization, bioeconomie and subjectivation processes: some \\ considerations on neoliberal government in the health market
}

Flávia Cristina Silveira Lemos; Dolores Galindo; Renata Vilela Rodrigues

Universidade Federal do Pará; Universidade Federal de Mato Grosso

\section{RESUMO:}

Neste ensaio, de natureza teórica, discutimos a medicalização da vida, em sua faceta neoliberal, e como esta se efetua em práticas que visam potencializar processos de subjetivação conduzem à formação de biocidadãos empreendedores de si e endividados. Para tal, as reflexões se pautam por contribuições de Michel Foucault e por contribuições recentes a respeito da bioeconomia e processos de subjetivação. Argumentamos que em confluência com as reflexões sobre biocapital e capital vivo, o governo da vida medicalizada requer uma dimensão produtiva e de capitalização subjetiva necessária à engrenagem neoliberal.

Palavras-chave: bioeconomia; biocidadania; neoliberalismo.

\begin{abstract}
:
In this theoretical essay, we discuss the medicalization of life, in neoliberal aspect, and how it is carried out in practices that aim at enhancing processes of subjectivation, lead to the formation of entrepreneurial and indebted bio-entrepreneurs. For this, the reflections are based on contributions of Michel Foucault and recent contributions on bioeconomics and processes of subjectivation. We argue that, in conjunction with the reflections on biocapital and living capital, the government of the medicalized life demands a productive dimension and subjective capitalization necessary to the neoliberal.
\end{abstract}

Key-words: bioeconomies; biocitizenship; neoliberalism.

DOI: 10.12957/mnemosine.2020.52698

\section{Introdução}

Este ensaio discute a medicalização da vida, em sua faceta neoliberal, e como esta se efetua em práticas que visam potencializar processos de subjetivação, os quais conduzem à formação de certos grupos de pessoas que vêm sendo chamados de biocidadãos, pois seriam empreendedores de si e vidas endividadas pela própria condição jurídica de cidadania. Trata-se de um estudo que faz parte de uma pesquisa maior sobre capitalização da vida nos avanços biotecnológicos em Medicina 
Regenerativa, que compõe parte de uma dissertação de mestrado. Todavia, não se limita a ela e amplia analíticas presentes em várias pesquisas, realizadas em duas universidades públicas, há cerca de treze anos.

Para realizar a análise proposta aqui, as reflexões são pautadas por contribuições de Michel Foucault sobre neoliberalismo e biopolítica, e pelas analíticas recentes a respeito da bioeconomia e dos seus efeitos nos processos de subjetivação, em especial, nos cursos: Segurança, território e população (2008a); O nascimento da biopolítica (2008b); O poder psiquiátrico (2006); Os anormais (2002) e Em defesa da sociedade (1999). Trata-se de cursos relevantes no debate a respeito da mercantilização da saúde, do governo da vida pela medicina social, da psiquiatrização generalizada e da gestão bioeconômica da população em prol do aumento da saúde e da ampliação de performances.

Bioeconomia refere-se a uma terminologia utilizada recentemente pela literatura científica e as organizações econômicas, a fim de discorrer sobre a comercialização e a manipulação tecnológica dos recursos biológicos e naturais. A bioeconomia diz do desenvolvimento de indústrias biotecnológicas e farmacêuticas na criação e na organização de novas patologias, no sequenciamento das estruturas genômicas que impulsionam pesquisas em setores públicos e privados sobre nossa existência enquanto seres biológicos, na bioética e na busca de lucro que englobam todas as instâncias da vida, convertendo-se também em preocupações biopolíticas (ROSE, 2013). Segundo Castiel (2010), a vida assume uma dimensão política que se torna passível de governar, administrar, calcular e normalizar por intermediação de ações bioeconômicas de empreendimentos privados transnacionais e políticas públicas de saúde.

Logo, a emergência de uma bioeconomia traz à tona novos espaços comerciais nos espaços de saúde e viabiliza a constituição de modos de subjetivação que se caracterizam como empresárias de si e endividadas. O empreendedor de si é apresentado por Foucault (2008) como o homem econômico, um empresário constituído de capital produzido pela economia neoliberal. O empresariamento de si alude a certo tipo de investimento realizado no nível do próprio sujeito, que passa a ser visto como empresa, cujas condições de vida são a renda de um capital. Ele investe em si para obter sua própria melhoria e emerge nas relações comerciais entre Estado e neoliberalismo.

Ademais, o presente texto está em confluência com as reflexões sobre o biocapital, ou seja, com o governo da vida medicalizada por um capital da vida que requer uma dimensão produtiva e de capitalização subjetiva, a qual extrapola as 
condições necessárias à engrenagem neoliberal (LAZZARATO, 2013). O biocapital se refere a uma conceituação para abarcar não apenas o modo como as empresas de saúde, ao apropriar-se dos avanços biotecnológicos, manipulam e gerenciam a vida, mas também um tipo de "moeda" ou "dinheiro" de novos agenciamentos sociais e econômicos, para que possamos compreender como se desenvolve a capitalização da vida nos mercados de saúde públicos e privados (HELMREICH, 2008; ROSE, 2011b; RAJAN, 2007).

A capitalização da vida tornou possíveis jogos de controle perenes em que o sujeito é aquele que está sempre endividado, visto ser um consumidor e uma extensão do empresariamento de si. Na economia atual, sempre se está devendo e, continuamente, novos métodos são criados para tornar um indivíduo mais saudável, portanto, uma subjetividade empreendedora/consumidora e endividada, segundo apontam Bernardes e Guareschi (2007).

Os efeitos negativos dos usos de dispositivos medicalizantes em nome da vida operariam lado a lado com as positividades dos mesmos como biocapital a ser gerenciado subjetivamente, socialmente, culturalmente, ecologicamente, economicamente e politicamente. Buscar otimizar a vida e aumentar as performances da mesma, ampliando a racionalidade mercadológica das subjetividades enquanto estilos de existências saudáveis e biossociais porque experimentam uma sociabilidade ancorada na biomedicina em cada pensamento, sentimento, emoção, relacionamento amoroso, ato de trabalho, amizade e até mesmo espiritualidade.

Conforme realçam Assmann e Stimilli (2014), a íntima relação entre técnicas de governamentalidade e tecnologias do eu precisa ser parte do nosso trabalho de reflexão político, pois sem ela não é possível, como antevia Michel Foucault, rastrear os efeitos da racionalidade neoliberal no governo da vida (ASSMANN \& STIMILLI, 2014). O poder pastoral, de acordo com Foucault (2008a), foi atualizado e transformado por práticas de apropriação em políticas de cuidado, na emergência do Estado Moderno. Esta modalidade de poder-saber hebraica era utilizada, na Antiguidade, para proteger e conduzir as condutas do rebanho de ovelhas em prol de uma segurança e da governamentalidade das almas.

A racionalidade do Estado securitário deixou de lado o governo das almas para conduzir as subjetividades individualizadas e em grupos com fins liberais de regular processos normalizadores. Nestes, os corpos e a saúde passavam a ser geridos por 
biotecnologias em uma economia política pautada na ordem e na lei enquanto modos de produzir subjetivação pela inflação jurídica e pela medicalização dos estilos existenciais - com objetivos de gerar um assujeitamento empresarial e empreendedor da saúde e das performances (FOUCAULT, 2008b).

Para Deleuze (1992), subjetividade é uma dobra, efeito de um conjunto de processos de subjetivação. Uma maneira de ser, de pensar, de agir, de sentir, de se relacionar e de viver é a subjetividade, e a subjetivação é a processualidade de constituição subjetiva forjada por práticas sociais, econômicas, políticas, culturais, ecológicas, espirituais, históricas, psicopedagógicas e médico-jurídicas. As disciplinas e saberes do desenvolvimento humano ofertam psiquiatrizações da sociedade como nunca desde o surgimento do conceito de infância e de mediação do desenvolvimento como evolução do pensamento e da razão. Ser saudável passou a ser um modo de ser desenvolvido e racional, resultante de uma forma de vida 'sujeito autônomo' (FOUCAULT, 2006).

Ter autonomia é saber os limites e potencialidades, e agir sobre ambos com tecnologias de si, as quais possam conduzir corpos e relações pelas biossociabilidades enquanto estímulos e investimentos subjetivos, bem como econômico-políticos, da vida. A soberania do sujeito ganhou centro em uma razão que opera por juízos de autocuidado e autoconhecimento, em um estilo de existência. Quem não se cuida supostamente não se governa; portanto, não ter saúde e/ou ter baixa performance/desempenho em qualquer instância é um sinal de ausência ou diminuição da autonomia e da razão, é um indicador de menoridade política e baixa capacidade contratual (CASTEL, 1988).

\section{Empreendorismos como uma formação de biocidadãos: biopolíticas e medicalização}

As políticas de subjetivação que se desenham no horizonte da bioeconomia conduzem, majoritariamente, a um empobrecimento dos modos de vida, já que as pessoas são instadas a investir ou perder e sair deste jogo, o qual requer contrainvestimentos. Fazem-se urgentes espaços de resistência a estes modos de subjetivação, uma vez que, paralelamente, visualizam-se sujeitos exaustos pelo excesso de estímulos bem como frente às perdas nos investimentos realizados e às demandas constantes de empreendedorismo com as quais se defrontam. 
O empreendedorismo de si em uma condição de biocidadão, investidor e endividado, tem lugar em uma cultura caracterizada por relações medicalizadas e medicalizantes, em que o fato de buscar infinitamente uma hiperprevenção das doenças e tentar garantir práticas de lidar com elas impulsiona um mercado modulado não só pelo biovalor de materiais biológicos, mas ainda pelo gerenciamento dos afetos, em uma cultura biopolítica, o qual opera ao sabor das encomendas dos mercados de investimentos. Conforme lembra Pelbart (2008), as sociedades neoliberais não precisam apenas de músculos e disciplinas, mas de imaginação, de inventividade e da própria vitalidade. Ou seja, a fonte de riqueza é, igualmente, o chamado capital cognitivo, a criatividade, a afetividade e, principalmente, os corpos saudáveis.

O biovalor é a prática de transformação de alguém em capital por meio da comercialização de fragmentos ou da totalidade de um corpo. A vida como valor de mercado se torna um biovalor, desta maneira. A economia política focada na vida criou uma racionalidade neoliberal da bioeconomia, em que a gestão da vida ganha um estatuto de governo pelo uso das biotecnologias. Gerir tecnicamente partes da existência pela capitalização da mesma é o efeito de uma sociedade empresarial em que tudo é alvo de lucro e entra no agenciamento dos investimentos no contemporâneo (SIBILIA, 2015).

Waldby (2000) sugere o emprego do termo biovalor para referir-se a um capital que surge quando a produtividade gerativa e transformativa das entidades vivas pode ser instrumentada de forma útil para projetos humanos em ciência, indústria, medicina e outras arenas da cultura técnica. O valor é uma disputa na cultura de trocas afetivas, sociais e políticas, na lógica empresarial das existências e na perspectiva do empreendedorismo que tudo deseja capitalizar.

A saúde e o cuidado têm sido cada vez mais pensados como atos normativos, sendo que a gestão da vida passa por um sistema regrado por normas e padrões produzidos como campo valorativo na lógica do capital gerencial, ou seja, a própria vida se torna capital a investir, a comprar e a vender como mercadoria. A biopolítica é o governo das condutas em prol do empresariamento da saúde e da vida, concomitantemente. Materializa-se pela psiquiatrização das existências, pela generalização do higienismo e controle normalizador da medicina social, por meio da segurança em nome da ordem e da lei com o aval do chamado Estado Democrático de 
Direito, o qual judicializa, medicaliza e comercializa a vida (FOUCAULT, 1999; 2002; 2006; 2008a; 2008b).

Como exemplos, é possível abordar e problematizar as práticas de governo da vida, as quais, hoje, são pautadas por uma política neoliberal, acentuando a emergência de uma bioeconomia que traz à tona um novo espaço de companhias, trabalhando com potenciais terapêuticos, em uma bioeconomia cuja ontologia é o capital vivo. Pesquisadores discutem a segurança de experimentos, outros não recomendam determinados tratamentos, enquanto alguns os indicam; tentam mediar em esferas internacionais essas decisões, em conferências da ONU, e buscam estabelecer acordos em pactos e declarações, resoluções, criação de metas e princípios a serem monitorados. Afirmam que, se não tomarem decisões coletivas e que avaliem âmbitos mais complexos, poderão destruir a vida e o futuro.

Tornamo-nos reféns da defesa da biocidadania num país em que o direito à saúde tem sido desmontado, nos últimos anos, com o aumento das ameaças de desmonte do Sistema Único de Saúde (SUS), o qual está cada vez mais ameaçado pela privatização dos equipamentos públicos na forma de seguros privados de saúde a baixo custo e por meio de outros dispositivos de governo, como o gerenciamento de hospitais por empresas privadas. Assim, reivindicar biodiagnósticos não pode ser visto como reivindicar meras ferramentas para estudar os corpos e prever doenças; são dispositivos de governo da vida e normalizações disciplinares que mapeiam potências do humano enquanto biocidadão. Mais do que em biodiagnosticos, o SUS se alicerça na garantia da saúde como direito e na participação da sociedade civil. Um exemplo emblemático pode ser encontrado na defesa do acesso universal aos medicamentos contra HIV/Aids no Brasil. As patentes foram "quebradas" com base na garantia de acesso ao melhor tratamento existente pelas pessoas vivendo com HIV/Aids e por meio de um amplo processo de luta da sociedade civil. Não era a busca reducionista de um biocapital o que estava em cena na quebra de patentes e distribuição da medicação antirretroviral na rede de Saúde, ainda que esta dimensão não fosse ausente na forma de biocidadania.

Os comitês de ética e a bioética são convocados a regular, analisar e lutar na arbitragem das escolhas e efeitos de tecnologias biodiagnósticas, as quais se vêm também reféns da destituição da legitimidade das resoluções que visam granjear limiares distintos para avaliar a pesquisa com seres humanos. Os conselhos de direitos, conferências e pareceres de especialistas, conselhos profissionais, agências reguladoras, organizações internacionais multilaterais e grandes corporações em saúde também são 
convidadas a integrar fóruns e comissões que avaliem custos e benefícios do empresariamento de si e dos outros.

Subjetiva-se para a autonomia individual e coletiva, ou seja, o sujeito de decisão é efeito do capital humano e de um capital social; governa a si e aos outros, na perspectiva de que decide sobre si e os outros, pensando a si mesmo e pensando com os outros a respeito da condução de si e dos coletivos, na noção de bem comum e de bemestar individual como efeitos de governo liberal. As subjetivações de biocidadãos endividados e empreendedores de si no contexto de fragilização do sistema público de saúde, no Brasil, é um anátema. Talvez os planos de saúde a preço inferior e a retirada dos direitos universais à saúde sejam acatados como parte de um cálculo no qual a vida vale cada vez menos e o biocapital apresentará as novas fronteiras que segregam os anormais, os restos. O conhecimento sobre a vida se torna um capital privilegiado e caro, pouco acessível, aplicado em níveis sóciotécnicos específicos (LAZZARATO, 2014).

Ser cidadão pela biologia como condição de avaliação diagnóstica passou a ser um modo de organizar formas de existir e pensar, em uma determinada sociedade. $\mathrm{O}$ chamado ser jurídico cidadão é alguém que obedece e serve a uma lei a qual o regula também como sujeito gerenciado pela condição de cidadania biológica, avaliada por especialistas e empresariada por um crescente mercado da vida. No bojo destas questões levantadas, é relevante apontar o quanto os diagnósticos, encaminhamentos equivocados e procedimentos arbitrários em nome do lucro passaram a fabricar mais adoecimento e problemáticas a gerenciar com mais tecnologias duras e caras no mercado da saúde. Produz-se uma bolsa de valores na qual o ativo é a Saúde a ser buscada na forma de vidas-investimento que se alicerçam na busca de controle de riscos potenciais (ORTEGA \& ZORZANELLI, 2010).

Trata-se uma bolsa de valores que beneficia grandes conglomerados médicofarmacêuticos e que, ao mesmo tempo, faz de cada sujeito um apostador que nunca sabe ao certo se tomou a decisão correta, pois o agenciamento coletivo é reduzido a uma lógica individualizada e incapaz de dar conta das tramas que a forjam. Não há vencedores nesta bolsa de biocapital, pois as patologias, técnicas diagnósticas e de tratamento flutuam em grau de certeza, de modo a gerar sujeitos em déficit quanto a uma nova tecnologia que se mostra mais eficiente que a anterior ou mesmo se mostram iatrogênicas em longo prazo (FREITAS \& AMARANTE, 2017). 


\section{Medicalização, capitalismo neogerencial e endividamento subjetivo}

A medicalização está inserida nos mais diversos e múltiplos âmbitos de nosso cotidiano. Seria ingênuo pensá-la como um impacto exclusivamente negativo, visto os importantes avanços da medicina, genética e farmacologia, os quais contribuíram para o aumento da qualidade de vida e longevidade das populações com acesso a esses recursos. Contudo, salientemos que estamos cada vez mais propensos a pensar a vida e suas nuances de modo extremamente reducionista (FREITAS \& AMARANTE, 2017).

A biomedicina repete a retórica da salvação da modernidade, a qual enfatiza o desenvolvimento de medidas tecnológicas, econômicas e políticas como condição para a salvação da civilização. O que não é de espantar, pois, como aponta Haraway (1995: 10), a própria Ciência é retórica, "é a convicção de atores sociais relevantes de que o conhecimento fabricado por alguém é um caminho para uma forma desejada de poder bem objetivo". Novas tecnologias de saúde são organizadas na imanência, quer dizer, na correlação ao acaso de forças com as mutações do mercado, com as transformações das famílias, com os efeitos ecológicos dos impactos ambientais, com as alterações da política e com a atualização das relações sociais e culturais.

As forças dos agenciamentos subjetivos são compostas por processos ininterruptos, os quais não cessam de vibrar e atravessar a dobra provisória da subjetividade, conforme pensou Deleuze (1992) acerca das sociedades de controle. Essas modulações de subjetivação se organizam como forças em agenciamentos coletivos, que operam por correlações sem causalidade e sem linearidade, na esfera dos acontecimentos que se cruzam e se conectam como teias sem privilégio de entradas e saídas das suas linhas de composição.

Ademais, em tempos de capitalismo neogerencial, as novas tecnologias de saúde estão cada vez mais sendo decididas pelos grandes conglomerados que definem as políticas de ações, algumas vezes à revelia dos próprios estados nacionais. Estas novas tecnologia se configuram a partir do aumento de suas taxas de lucro e da busca da hegemonia financeira num mundo sempre mais interdependente e complexo. Com isso, acionam processos de subjetivação modulados pelo endividamento em relação a um futuro incerto, acerca do qual é necessário manter precauções constantes (EHRENBERG, 2010).

Gerenciar no novo capitalismo é mais do que administrar finanças, implica em organizar os processos vitais, em capitalizar os afetos, a cultura, o conhecimento e a 
saúde em nome do lucro e do empreendedorismo. Este mecanismo gera uma dívida constante, uma sensação de débito grande e permanente, racionalizada pela encomenda de produzir vinte e quatro horas e, caso não aconteça desta maneira, sente-se culpa e recebem-se acusações de baixo desempenho e avaliações que solicitam aumento de performance (LAZZARATO, 2017).

Mal nos despedimos das esperanças perdidas com o fracasso da busca genômica que, apesar dos avanços, se mostrou incapaz de oferecer um mapa humano como se aguardava, já nos lançarmos numa aposta igualmente frágil, em busca de evitar qualquer ranço de imprevisibilidade futura. É preciso atentar para os modos, aparentemente antitéticos, de conjugação entre governo da vida e subjetividades, sendo o mercado da saúde um dos operadores que propiciam sua efetuação. Os terrenos da medicalização da vida na bioeconomia que arregimenta subjetivações empreendedoras são descontínuos e heterogêneos (SIBILIA, 2015).

Foucault (2008), no livro Nascimento da Biopolítica, traça a maneira como passamos de um regime liberal para um Estado do bem-estar social (keynesianismo) e, finalmente, no século XX, para uma governamentalidade neoliberal diferenciada do liberalismo. Tomando como exemplo a forma de governar de grande parte da Europa e dos Estados Unidos, Foucault (2008: 04), salienta que o liberalismo emerge, no século XVIII, como uma arte de governar os homens, suas condutas, suas ações e reações, "com base em algo que se chama Estado" e nas teorias econômicas de Adam Smith e dos fisiocratas.

As principais características do liberalismo são: (1) uma forma de verdade do mercado baseada na concorrência entres os Estados e com o objetivo de enriquecimento da economia estatal; tal concorrência só é possível na medida em que emerge uma economia política, que consiste num "método de governo capaz de assegurar a prosperidade de uma nação" ao manter o equilíbrio econômico entre os Estados (FOUCAULT, 2008: 19); (2) o mercado, ao estabelecer qual o preço justo a se pagar nessa relação concorrencial, é que discerne quais as práticas de governamentalidade são verdadeiras e quais são erradas, empregando com isso uma autolimitação do Estado pelo cálculo da utilidade governamental, e (3) o liberalismo é produtor de liberdade, uma vez que ele só funcionará, como razão governamental, se existirem liberdades individuais e econômicas. Contudo, essa liberdade é algo fabricado, pois é a razão do Estado, por meio de dispositivos de segurança, que vai decidir até que ponto as 
liberdades individuais e econômicas não constituem um perigo ao interesse de todos; portanto, os limites da prática governamental e a liberdade dos indivíduos são traçados pela própria esfera do Estado (FOUCAULT, 2008a).

No início do século XX, mais especificamente na década de 1930, aparecem políticas econômicas estatais voltadas para o bem-estar social, com o intuito de reverter uma crise econômica e social instaurada pela chamada Crise de 1929 e, posteriormente, pela queda da Alemanha Nazista, após a Segunda Guerra Mundial. Foucault (2008) mostra que essas políticas do bem-estar, conhecidas também como Escola Keynesiana, já que têm sua origem nas ideias político-econômicas de John Keynes, consistiam em políticas econômicas intervencionistas elaboradas entre 1930 e 1960 (FOUCAULT, 2008b).

Essas intervenções levaram a algo que Foucault denomina crise do liberalismo, manifestada em reavaliações e reformas nos projetos na arte de governar, na Alemanha, antes e imediatamente após a guerra, e nos Estados Unidos, pelo presidente Franklin Roosevelt, com o New Deal, que objetivava recuperar e restaurar a crise econômica dos Estados Unidos através de uma série de medidas econômicas, baseadas no bem-estar social. Por volta de 1970, o modelo do bem-estar social começa a ceder lugar para as ideias liberais, desenvolvidas no século XVIII, com pequenas modificações na governamentalidade estatal, a partir do desenvolvimento de uma fobia do Estado.

O surgimento do governamentalidade neoliberal, "na reflexão de Foucault, indica significativas transformações nas práticas de governo de pessoas, populações e da circulação de coisas" (RODRIGUES, 2013: 136). Nos processos neoliberais, o Estado tem por função regular uma gestão governamental intervencionista e exercer a vigilância sobre a sociedade. Em outras palavras, busca administrar as condutas das pessoas, sem destruir a sua existência e sua pretensa liberdade, o que é possível por meio da proliferação de especialistas - médicos, cientistas, agentes sociais - e da criação de alianças entre cidadãos livres e mercados internacionais (MILLER \& ROSE, 2012). A figura do sujeito empreendedor e endividado faz com quem cada um se torne um agente social e especialista da própria vida, aprendendo com as biotecnologias que é preciso proteger, cuidar e manter as vidas, que é preciso investir e prever danos.

Nessa direção, não é mais apenas o Estado que define o que é certo ou errado, mas a Economia de Mercado, cabendo à política estatal somente o papel de criar e preservar o marco institucional apropriado para o desenvolvimento de algumas práticas, como, por exemplo, garantir a qualidade e a integridade da economia, da população, 
assegurar os direitos de propriedade privada e dispor de um mecanismo potente de polícia. Assim, na arte de governar neoliberal, o Estado e a sociedade têm por função regular a vida e a saúde, para administrar as condutas das pessoas sem destruir a sua existência e autonomia. Essa autonomia é criada de modo permanente como direito de escolha e de decisão sobre o que concerne a si e aos outros.

Esse sujeito da opinião, na legitimidade da soberania jurídica, isto é, do plano de interesses na visão de poder como direito democrático a se manifestar e decidir representativamente, implica uma subjetivação liberal enquanto estilo de vida e não apenas o liberalismo como regime político e uma economia capitalista. Nesse sentido, Foucault (2008) aposta na análise de poder como individualização e totalização de condutas, disciplina e biopolítica, simultaneamente. Por isso, para Foucault (2008), o neoliberalismo passa a ser fundamental para o desenvolvimento de uma biopolítica e do capitalismo voltado para a liberdade política e econômica do Mercado, pois tem como alvo a população.

A diferença do liberalismo para o neoliberalismo é que a governamentalidade, no liberalismo, é ligada à planificação administrativa e ao financiamento público das políticas sociais. No neoliberalismo, o financiamento é delegado ao privado cada vez mais, e a individualização ganha importância, sendo que o coletivo fica mais vinculado à judicialização e à medicalização das condutas (FOUCAULT, 2008). Os direitos são ampliados a partir do mercado neoliberal e como investimentos, na gestão de riscos de adoecer, de perder o trabalho e emprego, de perder uma promoção, de perder os relacionamentos e de perder a vida e as oportunidades. Todavia, o cidadão deve manter a ordem e a paz, zelar pela segurança e pela saúde, cuidar de si e gerir sua comunidade, investir em relações de empreendimento e aumentar capitais diversos.

Duménil e Lévy (2011: 326) afirmam que o neoliberalismo entrou em crise no século XXI. Na última década, em especial em 2008, viveu-se o ápice de uma das crises estruturais do capitalismo (a do neoliberalismo) que, mesmo ainda sem clareza de seus desdobramentos futuros, estão levando a ajustes para continuar existindo. Assim, os processos de gestão e padronizações passariam a ser ainda mais gerenciados com vistas à retomada das dinâmicas geradoras de lucros e manutenção da ordem específica de controle da vida.

Especialistas ajudarão a formar subjetividades biocidadãs, as quais se antecipem nas decisões no plano das normas e mesmo da chamada mediação de conflitos: 
medicalização e judicialização da vida. Mais que biomedicina, medicalização é extensão da busca de bem-estar em tudo que fizermos e, mais que Poder Judiciário, judicialização é subjetivar-se por vida empresariada por contratos o tempo todo. Dessa maneira, especialistas prescrevem e não impõem, os mediadores auxiliam a decisão para a resolução de conflitos sem violência e não arbitram para obrigar a algo. Nesse aspecto, a autonomia ganha, no neoliberalismo, uma condição de decisão refletida pelo investimento medicalizante e judicializante das condutas.

Medicalizar é definir um objeto e um conjunto de práticas correlatas como um ato a ser explicado e administrado por uma perspectiva médica da existência. A vida, organizada como campo normativo de uma política do controle biológico da sociedade, entrou em um cálculo de controle político. Portanto, no bojo de uma racionalidade técnica, a vida como política do conhecimento e organização biológica da existência passa a ser esquadrinhada pelas regras biomédicas e pelas táticas biotecnológicas.

Em Os anormais (2002) e em Em defesa da sociedade (1999), fica patente a preocupação em hiperprevenir doenças e promover o gerenciamento preventivo da saúde pelo governo das condutas com vistas a proteger a sociedade e aumentar o rendimento da produção de todos os corpos, criando inclusões e capacitismos de toda sorte como tática de normalização social. Defender a sociedade pela psiquiatrização de toda a divergência e desvio das normas forja uma racionalidade racista generalizada, sendo a própria base da biopolítica contemporânea.

Regular antecipadamente as condutas e as probabilidades de uma situação cria um mercado de seguros não apenas econômicos, mas de biocapitais, biovalores, e uma bioeconomia cujos vetores de sustentação são a base da formação de biocidadãos governados pela biopolítica e por um conjunto de biotecnologias em nome da normalidade, da defesa social e da segurança da população.

\section{Considerações finais}

A maquinaria capitalista produziu sujeitos e objetos em variação contínua, modulados por tecnologias de gestão da vida (LAZZARATO, 2004). Vidasinvestimento se tornaram uma modalidade de subjetivação prevalente e dirigida, persecutoriamente, ao futuro. A esperança se tornou um modo de interação entre o presente e o futuro, uma vez que tê-la significa realizar ações direcionadas à construção de possíveis futuros desejáveis, ou seja, gerir o porvir pela previsibilidade contabilizada. Criar uma rede de esperanças, cautelas e precauções é um modo de organizar a vida das 
pessoas, visando a um futuro melhor; a pessoa é individual e coletiva, dado que permite a união de biografias individuais com interesses coletivos, processos sociais, econômicos e políticos, conforme pontua Novas (2006).

Para Hamilton (2008), deste modo, a bioeconomia delimita uma série de processos da política vital que vem acontecendo nas últimas décadas, em que elementos ditos da natureza adquirem valor e são estruturados em termos econômicos. Mas é importante ressaltar que a própria emergência do termo bioeconomia está ligada ao mercado transnacional de capital biológico da saúde, e apenas num momento posterior migrou como crítica a esse próprio movimento do qual surge. Como destacam Gonzáles et al. (2014), a palavra bioeconomia aparece pela primeira vez na literatura científica em 1913, no livro Evolution by cooperation: a study in bioeconomic, do biólogo Reinheimer, e somente em 1972 sua conceituação é realizada pelo matemático e economista Georgescu-Roegen.

As reflexões sobre bioeconomia se entrelaçam a uma mudança na forma de conceber a Ciência. Se antes tínhamos uma Ciência restrita a poucos e permeada de práticas biopolíticas liberais, atualmente vivenciamos uma política neoliberal permeada por práticas de biovalor, as quais mobilizam subjetivações articuladas aos discursos de afetividade, esperanças e precauções. O biovalor implica na compra e venda de células, materiais genéticos, criação de biotecnologias personalizadas para a produção da saúde por meio de um mercado de células-tronco, por exemplo.

Nesse conjunto conceitual, a adoção do termo biocapital se tornou a "moeda" vigente no meio acadêmico, a fim de dizer da utilização lucrativa dos desenvolvimentos contemporâneos em Ciência Biológica. Tal terminologia deriva do conceito de biopolítica, em Foucault (2008), e consiste no processo por meio do qual o material e/ou informação biológica são transformados em empreendimentos políticos e econômicos de valor. O biocapital está enredado nas configurações econômicas sociais e nas relações de reprodução e parentesco; ele emerge quando as substâncias e as promessas terapêuticas com o emprego do material biológico são inseridas no mercado e se tornam produtos com finalidade lucrativa porque implicam em uma oferta intensa de tecnologias de saúde comercializadas, compradas e vendidas como esperança de vida longa (HELMREICH, 2008).

A noção de biocapital surge para dar conta de um contexto no qual a materialidade e as promessas dos materiais biológicos arregimentam grandes 
investimentos comerciais, transnacionais e locais. Em outras palavras, o biocapital concerne a uma conceituação para discorrer não apenas sobre a forma como as empresas comerciais, ao apropriar-se dos avanços biotecnológicos, manipulam e gerenciam a vida, mas também a um tipo de "moeda" ou "dinheiro" de novos agenciamentos sociais e econômicos, para que possamos compreender como se desenvolve a capitalização das biotecnologias (HELMREICH, 2008; ROSE, 2011).

Uma vida tecida e constituída como investimento se torna objeto de mercantilização constante, nos mínimos detalhes de sua condição, desde a biológica até a social, cultural, subjetiva, afetiva, política e econômica. Todo o processo vital é forjado como portador de preço, de valor no mercado de compra e venda, de possíveis trocas e intercâmbios comerciais. Com efeito, fragmentos dos corpos também se tornam capitais, passando a ser definidos enquanto biocapitais e o mercado dos mesmos se torna dependente de um campo cultural, denominado biovalor, pois opera uma cultura somática capitalizada ao extremo.

$\mathrm{Na}$ atualidade, o capital não precisa apenas de músculos e disciplinas, mas de imaginação, de inventividade e da própria vitalidade. Quer dizer, sua fonte de riqueza pressupõe, agora, a inteligência das pessoas, sua criatividade, sua afetividade e, principalmente, seu corpo e o seu desenvolvimento saudável (PELBART, 2008). Lazzarato (2004), ao discorrer sobre o modo contemporâneo de produção do capital, argumenta que o capitalismo produz sujeitos e objetos em variação contínua, modulada por tecnologias de gestão da vida. O que o autor propõe é uma forma de enxergar o capital não somente em relação ao trabalho, de forma reducionista, mas em relação a todos os aspectos da existência.

Nós estamos nos tornando sujeitos endividados e empreendedores de um capital que nos é expropriado - a vida. As lutas por pequenas reformas em planos de previdência privada não alteram o jogo de forças que desmantela os ataques ao Sistema Único de Saúde do Brasil. Reivindicar terapêuticas e novas tecnologias sem atrelá-las à defesa de um estado mínimo de bem-estar nos leva a agentes de uma bolsa de valores que, ao final do dia, retorna para casa exausto de calcular e ralhar com outros num jogo que já está vencido. É preciso mudar o nosso vocabulário de subjetivação e sair do investimento infinito nas cidadanias biológicas (SILVA, 2017).

Finalizando, biovalor, biocapital, biotecnologia e biocidadania se tornam parte de um vocabulário cada vez mais utilizado em um crescente mercado da saúde e da vida atualmente, o qual funciona pela gestão empreendedora dos direitos, em especial o de 
acesso à saúde e à vida. Adquirir saúde e mercantilizar a esperança no futuro gera lucro e tranquiliza subjetividades ávidas por segurança e longevidade.

\section{Referências}

ASSMANN, S. J., \& STIMILLI, E. Per una vita in debito. Exercícios para uma vida em débito. Revista Internacional Interdisciplinar INTERthesis, 11(2), 248-265, 2014.

CAPONI, S. Loucos e Degenerados: uma genealogia da psiquiatria ampliada. Rio de Janeiro: Fiocruz, 2014.

CONRAD, P., \& LEITER, V. Medicalization, Markets and Consumers. Journal of Health and Social Behavior, 45, 158-176, 2004.

DELEUZE, G. Conversações. Rio de Janeiro: Editora 34. (Originalmente publicado em 1990), 1992.

DUMENIL, G., \& LEVY, D. The Crisis of Neoliberalism. Cambridge, Massachusetts: Harvard University Press, 2011.

EHRENBERG, A. O culto da performance. Da aventura empreendedora à depressão nervosa. Aparecida-SP: Ideias \& Letras, 2010.

FOUCAULT, M. Em defesa da sociedade. São Paulo: Martins Fontes, 1999.

FOUCAULT, M. Os anormais. São Paulo: Martins Fontes, 2002.

FOUCAULT, M. O poder psiquiátrico. São Paulo: Martins Fontes, 2006.

FOUCAULT, M. Segurança, território, população. São Paulo: Martins Fontes, 2008a.

FOUCAULT, M. O Nascimento da Biopolítica. São Paulo: Martins Fontes. (Original publicado em 1978-1979), 2008b.

FREITAS, F. \& AMARANTE, P. Medicalização em Psiquiatria. Rio de Janeiro: FIOCRUZ, 2017.

GONZÁleZ, C. A. Z., PAlOMARES, R. D., CURA, R. A. R., AGUILAR, A., ROA, N. E. B., TORUÑO, P. J., ANTÓN, W. S., \& HERNÁNDEZ, A. J. C. La Bioeconomía: Una nueva perspectiva de la Economía. In: RED CYTED, Red de Bioeconomía y Cambio Climático (REBICAMCLI) (Org.). Estado del arte de la bioeconomía y el cambio climárico, (pp. 2-25). Universidad Nacional Autónoma de Nicaragua: Editorial Universitaria, 2014.

HAMILTON, C. Intellectual property rights, the bioeconomy and the challenge of biopiracy. Genomics, Society and Policy, 4(6), 26-45, 2008.

HARAWAY, D. Saberes localizados: a questão da ciência para o feminismo e o privilégio da perspectiva parcial. Cadernos Pagu, (5), 07-41, 1995.

HELMREICH, S. Species of Biocapital. Science as culture, 17(4), 463-478, 2008. 
IGNÁCIO, V. T. G., \& NARDI, H. C. A medicalização como estratégia biopolítica: um estudo sobre o consumo de psicofármacos no contexto de um pequeno município do Rio Grande do Sul. Psicologia \& Sociedade, 19(3), 88-95, 2007.A

LAZZARATO, M. From capital-labour to capital-life. Ephemera, 4(3), 187-208, 2004.

LAZZARATO, M. O governo do homem endividado. São Paulo: N-1, 2017.

LAZZARATO, M. Biopolítica/Bioeconomia. In I. C. F. Passos (Org.). Poder, normalização e violência: incursões foucaultianas para a atualidade. (2a. ed.) Belo Horizonte: Autêntica, 2013.

LAZZARATO, M. O governo do homem endividado. São Paulo: N-1, 2017.

MAI, L. D., \& ANGERAMI, E. L. S. Eugenia negativa e positiva: significados e contradições. Rev. Latino-Am. Enfermagem, 14(2), 251-258, 2006.

MARTINS, A. L. B. Biopsiquiatria e bioidentidade: política da subjetividade contemporânea. Psicol. Soc., 20(3), 331-339, 2008.

MILLER, P., \& ROSE, N. Governando o presente: gerenciamento da vida econômica, social e pessoal. São Paulo: Paulus. (Originalmente publicado em 2008), 2012.

NOVAS, C. The political economy of hope: patients' organizations, Science and biovalue. BioSocieties, 1, 289-305, 2006.

ORTEGA, F. \& ZORZANELLI, R. Corpo em evidência. A ciência e a redefinição do humano. Rio de Janeiro: Civilização Brasileira, 2010.

PALMA, A., \& VILAÇA, M. M. Conflitos de interesse na pesquisa, produção e divulgação de medicamentos. Hist. cienc. saude-Manguinhos, 19(3), 2012.

PELBART, P. Vida e morte em contexto de dominação biopolítica. Anais do Fundamentalismo Contemporâneo em Questão. São Paulo, SP, Brasil, 1-21 2008.

RODRIGUES, T. Ecopolítica e segurança: a emergência do dispositivo diplomáticopolicial. Revista Ecopolítica, (5), 115-156, 2013.

ROLNIK, S. Toxicômanos de identidade: subjetividade em tempo de globalização. In D. Lins (Org.). Cultura e subjetividade: saberes nômades, (pp. 19-24). São Paulo: Papirus, 1997.

ROSE, N. Biopolítica molecular, ética somática e o espírito do biocapital. (L. H. S. Santos, \& M. I. E. Bujes, Trad.). In L. H. S. Santos, \& P. R. C. Ribeiro (Orgs.). Corpo, gênero e sexualidade: instâncias e práticas de produção nas políticas da própria vida, (pp. 13-32). Rio Grande: FURG. (Originalmente publicado em 2006), 2011.

ROSE, N. A política da própria vida: biomedicina, poder e subjetividade no século XXI. São Paulo: Paulus. (Originalmente publicado em 2007), 2013.

SIBILIA, P. O homem pós-orgânico. A alquimia dos corpos e das almas à luz das tecnologias digitais. Rio de Janeiro: Contraponto, 2015.

SILVA, A.C. Corpos no limite. Suplementos alimentares e anabolizantes em academias de ginástica. Jundiaí-SP: Paco, 2017. 
STAUB, M. L., \& HOCH, V. A. A utilização de psicofármacos no tratamento de saúde mental. Disponível em http://www.sed.sc.gov.br. Acesso em 27 de novembro de 2013.

TESSER, C. D. Medicalização social (I): o excessivo sucesso do epistemicídio moderno na saúde. Interface (Botucatu), Botucatu, 10(19), 2006a.

TESSER, C. D. Medicalização social (II): limites biomédicos e propostas para a clínica na atenção básica. Interface (Botucatu), Botucatu, 10(20), 2006b.

WALDBY, C. The Visible Human Project: informatic bodies and posthuman medicine. London and New York: Routledge, Taylor \& Francis Group, 2000.

Flávia Cristina Silveira Lemos

Profa Dra. Associada II de Psicologia Social - UFPA. Instituto de Filosofia e Ciências Humanas - UFPA. E-mail: flaviacslemos@gmail.com

Dolores Galindo

Profa Dra. Associada II de Psicologia Social - UFMT. Programa de Pós-graduação em Estudos da Cultura Contemporânea.

E-mail: dolorescristinagomesgalindo@gmail.com

Renata Vilela Rodrigues

Psicóloga-UFMT

Mestre em Estudos da Cultura Contemporânea-UFMT. Programa de Pós-graduação em Estudos da Cultura Contemporânea. E-mail: renatinha.vilela@gmail.com 